\title{
Eating habits in the population of the Aeolian Islands: an observational study
}

\author{
Paolo La Spina ${ }^{1, *}$, Rodolfo Savica ${ }^{2}$, Antonio Ciacciarelli ${ }^{1}$, Masina Cotroneo ${ }^{1}$, \\ Cristina Dell'Aera ${ }^{1}$, Francesco Grillo ${ }^{1}$, Carmela Casella ${ }^{1}$, Maria Carolina Fazio ${ }^{1}$, \\ Giuseppe Trimarchi ${ }^{3}$ and Rosa Fortunata Musolino ${ }^{1}$ \\ 'Department of Clinical and Experimental Medicine, University of Messina, Via Consolare Valeria, 98125 Messina, \\ Italy: ${ }^{2}$ Department of Neurology, Mayo Clinic, Rochester, MN, USA: ${ }^{3}$ Department of Economy, University of \\ Messina, Messina, Italy
}

Submitted 14 June 2018: Final revision received 22 September 2018: Accepted 26 October 2018: First published online 26 December 2018

\begin{abstract}
Objective: We conducted a study to describe food profile, health status and stroke risk factors in the population of the Aeolian Islands.

Design: Self-administrated questionnaires regarding eating habits, health status and stroke risk factors were obtained from a sample of the general Aeolian population. We analysed the difference from common healthy eating habits indicated by the Italian Institute of Nutrition.

Setting: Current evidence finds the Mediterranean diet is a protective factor for cardio- and cerebrovascular diseases. The Aeolian Islands are an interesting study setting because of their peculiarity in the epidemiology of cerebrovascular and neurodegenerative diseases.

Participants: Individuals ( $n$ 586; age range 15-93 years; mean 52 (SD 18) years) living in the Aeolian Islands.

Results: We found low fish consumption in $13.3 \%$ and vitamin intake deficiency in $5.8 \%$ of participants. A marked excess of saturated fats was observed in $71.0 \%$ of participants. Sodium excess was reported almost in half of participants (49.0\%). Eating habits were characterized by high consumption of fruits and vegetables, consistent use of olive oil and scanty use of cured meat. Health status as evaluated by the General Health Questionnaire was characterized by 'normal distress' level in the majority of participants.

Conclusions: Study findings show the eating habits and health status of the Aeolian people in an interesting setting of low incidence of cerebrovascular disease. This nutrition regimen has been proved to be protective against cerebrovascular disease. Nutrition is likely to contribute to the low incidence of stroke in this population.
\end{abstract}

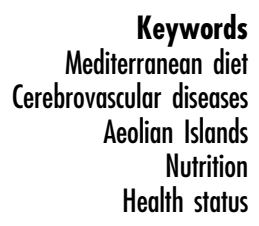

The Aeolian Islands are part of the Mediterranean basin and are an interesting study setting since they can serve as an example of the Mediterranean cradle and because of their peculiarity in the epidemiology of cerebrovascular diseases $^{(1)}$, epilepsy $^{(2)}$ and neurodegenerative diseases ${ }^{(3)}$. In this area the incidence and prevalence of these conditions are, indeed, lower than in other developed areas.

Mediterranean diet not only indicates nutritional education, but it is a concept that involves behavioural and lifestyle recommendations inspired by foods and ingredients available in the Mediterranean area. It represents a standard of healthy eating that aims to improve the global health status of the individual and to promote an improvement of the quality of life ${ }^{(4)}$. The diet is based mainly on some ingredients such as vegetables, fruits and fish, and a moderate wine consumption during meals. Previous findings reported that strict adherence to the Mediterranean diet is associated with a significant overall health improvement, a reduction in total and cardiovascular mortality, cancer morbidity and mortality ${ }^{(5-11)}$, and a decrease in the risk of neurodegenerative conditions such as Parkinson's and Alzheimer's diseases ${ }^{(12-17)}$, as well as the risk of stroke ${ }^{(18-24)}$. Altogether, the currently available evidence suggests that the Mediterranean diet may be a protective factor against cardio- and cerebrovascular diseases $^{(25-27)}$. 
A previous epidemiological study performed on the population of the Aeolian Islands demonstrated a lower incidence rate of first-ever stroke compared with similar Italian or international studies ${ }^{(1)}$. Thus, we conducted the present study to describe the food profile, health status and stroke risk factors in the population of the Aeolian Islands to investigate if dietary habits of the Aeolian people differ from other regions.

\section{Methods}

\section{Setting and study population}

The Aeolian Islands include seven Sicilian volcanic islands off the north-eastern coast of Sicily. Population count was 13431 inhabitants at the 2001 census and is equally distributed among urban and rural areas. Agriculture, fisheries and tourism are the main working activities. The climate is Mediterranean, with mild winters (temperature does not reach $0^{\circ} \mathrm{C}$ ) and hot and sunny summers (the highest temperature recorded is $39^{\circ} \mathrm{C}$ ). Medical care is guaranteed from the National Health Service, through ten general practitioners, ten first-aid stations and one public general hospital.

We considered all individuals $>14$ years old registered in the lists of the general practitioners in the Aeolian Islands. All general practitioners in the Aeolian Islands accepted to collaborate in the present study. Data from the general practitioners' electronic databases included clinical and demographic information regarding the entire population of the Aeolian Islands. Individuals unable to feed autonomously or undergoing any type of enteral or parenteral nutrition were excluded. Randomly selected individuals were telephonically contacted by their general practitioner and invited to a face-to-face interview within two weeks.

\section{Study design}

All enrolled participants filled in self-administered questionnaires regarding: (i) eating habits (FFQ); (ii) health status (General Health Questionnaire (GHQ)); and (iii) stroke risk factors (familiarity of stroke, hypertension, cigarette smoking, dyslipidaemia, CVD, diabetes mellitus and cerebrovascular disorders, oral contraceptives use and headache).

The FFQ is the most common dietary assessment tool used in large epidemiological studies of diet and health and has been recently validated in the Italian language ${ }^{(28)}$. The self-administered FFQ booklet asks participants to report weekly frequency of consumption, portion size and distribution of meals. Nutrient analyses were performed by computer software (Diet*Calc Analysis Program version 1.4.3; National Cancer Institute, 2005), thus obtaining deviations from eating habits indicated in the 'Guidelines for healthy feeding' from the Italian Institute of Nutrition and identifying the main mistakes and nutritional risk factors. Findings of the FFQ were also used to indirectly assess total energy intake and vitamin deficiency using the same software analyses.

The $\mathrm{GHQ}^{(29)}$ is a self-administered report that measures three aspects of psychological health status: (i) depression and anxiety; (ii) social dysfunction; and (iii) loss of trust. Based on the participants' answers, a score of psychological distress was computed for each of them: (i) $<16$ (normal); (ii) 16-20 (medium); and (iii) >20 (severe).

To better assess eating habits according the age-related stroke risk factors, we divided the population into three subgroups: (i) $<46$ years; (ii) $46-65$ years; and (iii) $>65$ years.

\section{Sample size calculation and statistical analysis}

The sample size was determined considering the number of inhabitants at the 2001 census ( $N 13431)$ aged between 15 and 93 years, stratified by sex and age group, by means of the following equation:

$$
n=\frac{z_{\alpha / 2}^{2} N}{4(N-1) \theta^{2}+z_{\alpha / 2}^{2}},
$$

where $1-\alpha$ is the CI, $z_{\alpha / 2}$ is the value of the standard normal and $\theta$ is the error margin. Thus, we obtained $n 586$ as a representative sample size of the Aeolian population, considering a level of confidence equal to $90 \%$ and the error margin equal to $3 \%$.

We calculated the percentage rate and related $95 \% \mathrm{CI}$ of eating habit deviations from the Italian Institute of Nutrition guidelines and the percentage frequencies of BMI categories, stroke risk factors, FFQ and GHQ scores. For consumption of the principal ingredients, as listed in the FFQ, ' $1+2$ times', ' $4+5+6$ times' and 'more than 6 times + in every meal' were merged together, to make data more reliable. When considering age group $(<46,46-65$ and $>65$ years old), absolute frequencies were compared with the $\chi^{2}$ test. The level of significance was set at $P<0 \cdot 05$.

\section{Results}

Initially, 671 individuals were contacted for the enrolment. Eighty-five denied their consent or refused to participate. A total of 586 individuals (age range 15-93 years; mean 52 (SD 18) years) accepted to participate in the study; 267 were men (45.6\%) and 319 women (54.4\%). Participants' characteristics and stroke risk factors are shown in Table 1; $6 \cdot 3 \%$ suffered from diabetes and $1.27 \%$ had a previous stroke. Almost $40 \%$ of the study population was overweight and almost $40 \%$ was normal weight.

\section{Eating babits}

Weekly consumption frequencies of main foods (percentage rates) are summarized in Table 2. Percentage rates 
and $95 \% \mathrm{CI}$ of deviations from the Italian Institute of Nutrition guidelines are shown in Tables 3-5. Data from the FFQ evidenced low fish consumption in $13.3 \%$ and vitamin intake deficiency in $5.8 \%$ of the participants. Excess intake of simple sugars and of animal protein was observed in 8.9 and $5.0 \%$, respectively. We did not observe large differences between males and females

Table 1 Characteristics and conventional stroke risk factors of the Aeolian population sample ( $n$ 586), June 2007

\begin{tabular}{|c|c|c|}
\hline Characteristic/risk factor & $n$ & $\%$ \\
\hline $\begin{array}{l}\text { Age (years), mean } \\
\text { SD }\end{array}$ & 586 & $\begin{array}{l}52 \\
18\end{array}$ \\
\hline Sex (male) & 267 & $45 \cdot 6$ \\
\hline Migraine (and headache) & 129 & $22 \cdot 0$ \\
\hline Hypertension & 120 & 20.5 \\
\hline Smoke & 84 & $14 \cdot 3$ \\
\hline Hypercholesterolaemia & 79 & 13.5 \\
\hline Familiarity for stroke & 67 & 11.5 \\
\hline Cardiopathy & 43 & $7 \cdot 3$ \\
\hline Diabetes & 37 & $6 \cdot 3$ \\
\hline Oral contraceptives & 19 & 3.2 \\
\hline Previous stroke & 7 & 1.3 \\
\hline \multicolumn{3}{|l|}{ BMI } \\
\hline Severe thinness $\left(<16.0 \mathrm{~kg} / \mathrm{m}^{2}\right)$ & 1 & 0.2 \\
\hline Moderate thinness $\left(16.0-16.9 \mathrm{~kg} / \mathrm{m}^{2}\right)$ & 3 & 0.4 \\
\hline Underweight $\left(17.0-18.5 \mathrm{~kg} / \mathrm{m}^{2}\right)$ & 22 & $2 \cdot 6$ \\
\hline Normal weight $\left(18.5-24.9 \mathrm{~kg} / \mathrm{m}^{2}\right)$ & 230 & $39 \cdot 4$ \\
\hline Overweight $\left(25 \cdot 0-29.9 \mathrm{~kg} / \mathrm{m}^{2}\right)$ & 220 & $37 \cdot 6$ \\
\hline Moderate obesity $\left(30.0-39.9 \mathrm{~kg} / \mathrm{m}^{2}\right)$ & 108 & 18.5 \\
\hline Severe obesity $\left(\geq 40.0 \mathrm{~kg} / \mathrm{m}^{2}\right)$ & 7 & 1.3 \\
\hline
\end{tabular}

except for sodium and calcium intakes. Interestingly, we observed a marked excess of saturated fats $(71.0 \%$ of people), especially in younger participants. Sodium excess was found almost in half of the participants (49.0\%). When considering age groups, we noticed less inappropriate energy intake and less sodium excess in people aged $>65$ years. Notably, the Aeolian population exhibited a high consumption of olive oil $(77 \cdot 7 \%$ used it every day), a very low use of other fats (seed oil, butter, margarine), a scanty use of cured meat ( $60 \%$ never used it) and a low consumption of milk products.

Although not statistically significant, participants aged $>65$ years showed higher fibre deficiency ( $40 \cdot 3 \%$ ), people aged 46-65 years showed high excess of fats $(36.7 \%)$ and, notably, higher excess of simple sugars was observed in younger participants $(12 \cdot 2 \%)$.

Data on daily alcohol consumption are shown in Table 6. Alcohol consumption was very scanty: almost $95 \%$ of the population denied intake of beer or hard liquor. Wine was consumed in moderation $(23.6 \%$ consumed one or two glasses of wine daily).

\section{Health status}

The GHQ evidenced a 'normal distress' level in the majority of participants, whereas a significant increase of 'severe distress' was observed in older people ( $>65$ years old; Table 7).

Table 2 Weekly consumption frequencies of main foods (percentage rates) in the Aeolian population sample ( $n$ 586), June 2007

\begin{tabular}{|c|c|c|c|c|c|c|}
\hline & \multicolumn{2}{|c|}{ Cereals } & \multicolumn{4}{|c|}{ Vegetables-legumes-fresh fruit } \\
\hline & Pasta/rice & Bread/crackers & Vegetables & Legumes & Minestrone & Fresh fruit \\
\hline Never or rarely & $10 \cdot 3$ & $23 \cdot 8$ & $13 \cdot 5$ & $13 \cdot 5$ & $29 \cdot 1$ & $13 \cdot 9$ \\
\hline $1-2$ portions & 8.9 & $2 \cdot 0$ & $16 \cdot 9$ & $45 \cdot 7$ & $48 \cdot 1$ & $5 \cdot 1$ \\
\hline 3 portions & $10 \cdot 1$ & $4 \cdot 1$ & $22 \cdot 8$ & $23 \cdot 1$ & 11.5 & $2 \cdot 7$ \\
\hline 4-7 portions & $47 \cdot 3$ & 32.9 & 39.0 & $16 \cdot 1$ & $10 \cdot 3$ & 32.9 \\
\hline \multirow[t]{3}{*}{ Each meal or almost } & 23.5 & $37 \cdot 2$ & 7.7 & 1.5 & $1 \cdot 0$ & $45 \cdot 4$ \\
\hline & \multicolumn{3}{|c|}{ Meat/fish } & \multicolumn{3}{|c|}{ Milk products } \\
\hline & Meat & Cured meat & Fish & Cheese & Milk & Yoghurt \\
\hline Never or rarely & $38 \cdot 4$ & 59.9 & $15 \cdot 7$ & $50 \cdot 0$ & 63.5 & $81 \cdot 8$ \\
\hline $1-2$ portions & $15 \cdot 9$ & 18.5 & 44.5 & 14.7 & $6 \cdot 0$ & $7 \cdot 4$ \\
\hline 3 portions & $22 \cdot 1$ & 8.7 & $18 \cdot 7$ & $12 \cdot 3$ & 3.9 & 4.4 \\
\hline 4-7 portions & $21 \cdot 6$ & $12 \cdot 2$ & $18 \cdot 8$ & 19.9 & 20.7 & $5 \cdot 5$ \\
\hline \multirow[t]{2}{*}{ Each meal or almost } & $2 \cdot 0$ & $0 . \overline{7}$ & $2 \cdot 2$ & $3 \cdot 1$ & $5 \cdot 8$ & 0.9 \\
\hline & Eggs & Sweets & & & & \\
\hline Never or rarely & 25.4 & 29.9 & & & & \\
\hline $1-2$ portions & $54 \cdot 7$ & 41.9 & & & & \\
\hline 3 portions & $12 \cdot 9$ & $9 \cdot 3$ & & & & \\
\hline 4-7 portions & $5 \cdot 4$ & $15 \cdot 6$ & & & & \\
\hline \multirow[t]{3}{*}{ Each meal or almost } & $1 \cdot 0$ & $3 \cdot 4$ & & & & \\
\hline & \multicolumn{5}{|c|}{ Added fats during or after preparation } & \\
\hline & Olive oil & Seed oil & Butter & Margarine & Mayonnaise & \\
\hline Never or rarely & $9 \cdot 8$ & $93 \cdot 8$ & 97.9 & $99 \cdot 3$ & $96 \cdot 4$ & \\
\hline Often & $12 \cdot 5$ & $4 \cdot 8$ & 1.9 & 0.5 & 2.4 & \\
\hline Always or almost & 77.7 & 1.4 & 0.2 & 0.1 & $1 \cdot 2$ & \\
\hline
\end{tabular}


Table 3 Percentage rates (and $95 \% \mathrm{Cl}$ ) of deviations from the Italian Institute of Nutrition guidelines among the Aeolian population sample (n 586), June 2007

\begin{tabular}{|c|c|c|c|}
\hline & $n$ & $\%$ & $95 \% \mathrm{Cl}$ \\
\hline Excess of saturated fats & 415 & $71 \cdot 0$ & $67 \cdot 1,74 \cdot 6$ \\
\hline Inappropriate energy distribution & 397 & $67 \cdot 9$ & $64 \cdot 0,71 \cdot 7$ \\
\hline Calcium intake deficiency & 356 & $60 \cdot 9$ & $56 \cdot 8,64 \cdot 9$ \\
\hline Sodium excess & 286 & $49 \cdot 0$ & $44 \cdot 8,53 \cdot 1$ \\
\hline Energy excess & 276 & $47 \cdot 1$ & $43 \cdot 0,51 \cdot 2$ \\
\hline Fibre deficiency & 213 & 36.5 & $32 \cdot 6,40 \cdot 6$ \\
\hline Fats excess & 185 & $31 \cdot 8$ & $28 \cdot 0,35 \cdot 7$ \\
\hline Low fish intake & 78 & $13 \cdot 3$ & $10 \cdot 7,16 \cdot 3$ \\
\hline Excess of simple sugars & 51 & 8.9 & $6 \cdot 7,11 \cdot 5$ \\
\hline Vitamin intake deficiency & 34 & $5 \cdot 8$ & $4.0,8.0$ \\
\hline Excess of animal protein & 28 & $5 \cdot 0$ & $3 \cdot 3,7 \cdot 0$ \\
\hline
\end{tabular}

Table 4 Percentage rates (and $95 \% \mathrm{Cl}$ ) of deviations from the Italian Institute of Nutrition, by sex, among the Aeolian population sample ( $n$ 586), June 2007

\begin{tabular}{|c|c|c|c|c|c|c|c|}
\hline & \multicolumn{3}{|c|}{ Females } & \multicolumn{3}{|c|}{ Males } & \multirow[b]{2}{*}{$x^{2}$} \\
\hline & $n$ & $\%$ & $95 \% \mathrm{Cl}$ & $n$ & $\%$ & $95 \% \mathrm{Cl}$ & \\
\hline Inappropriate energy distribution & 206 & 64.6 & $59 \cdot 0,69 \cdot 8$ & 192 & 71.9 & $66 \cdot 1,77 \cdot 2$ & 3.5 \\
\hline Energy excess & 142 & 44.5 & $39 \cdot 0,50 \cdot 2$ & 134 & $50 \cdot 2$ & $44 \cdot 0,56 \cdot 3$ & 1.9 \\
\hline Excess of animal protein & 14 & 4.4 & $2 \cdot 4,7.3$ & 15 & $5 \cdot 6$ & $3 \cdot 2,9 \cdot 1$ & 0.5 \\
\hline Excess of saturated fats & 221 & $69 \cdot 2$ & $63 \cdot 9,74 \cdot 3$ & 195 & 73.0 & $67 \cdot 3,78 \cdot 3$ & 1.0 \\
\hline Fats excess & 98 & $30 \cdot 7$ & $25 \cdot 7,36 \cdot 1$ & 88 & 33.0 & $27 \cdot 4,38.9$ & 0.3 \\
\hline Excess of simple sugars & 24 & 7.5 & $4.9,11.0$ & 28 & $10 \cdot 5$ & $7 \cdot 1,14 \cdot 8$ & 1.6 \\
\hline Sodium excess & 144 & $45 \cdot 1$ & $39 \cdot 6,50 \cdot 8$ & 143 & 53.6 & $47 \cdot 4,59 \cdot 6$ & $4 \cdot 1^{*}$ \\
\hline Fibre deficiency & 108 & 33.9 & $28 \cdot 7,39.3$ & 106 & 39.7 & $33 \cdot 8,45 \cdot 8$ & $2 \cdot 1$ \\
\hline Calcium intake deficiency & 181 & $56 \cdot 7$ & $51 \cdot 1,62 \cdot 2$ & 176 & $65 \cdot 9$ & $59.9,71.6$ & $5 \cdot 1^{*}$ \\
\hline Vitamin intake deficiency & 14 & 4.4 & $2 \cdot 4,7.3$ & 20 & 7.4 & $4 \cdot 6,11 \cdot 3$ & 2.6 \\
\hline Low fish intake & 46 & 14.4 & $10 \cdot 8,18.8$ & 32 & $12 \cdot 0$ & $8 \cdot 3,16 \cdot 5$ & 0.7 \\
\hline
\end{tabular}

Significant difference between men and women: ${ }^{\star} P<0.05$.

Table 5 Percentage rates (and $95 \% \mathrm{Cl}$ ) of deviations from the Italian Institute of Nutrition, by age group, among the Aeolian population sample ( $n$ 586), June 2007

\begin{tabular}{|c|c|c|c|c|c|c|c|}
\hline & \multicolumn{2}{|c|}{ Age $<46$ years } & \multicolumn{2}{|c|}{ Age $46-65$ years } & \multicolumn{2}{|c|}{ Age $>65$ years } & \multirow[b]{2}{*}{$x^{2}$} \\
\hline & $\%$ & $95 \% \mathrm{Cl}$ & $\%$ & $95 \% \mathrm{Cl}$ & $\%$ & $95 \% \mathrm{Cl}$ & \\
\hline Excess of saturated fats & $80 \cdot 2$ & $74 \cdot 2,85 \cdot 4$ & 71.7 & $65 \cdot 1,77 \cdot 6$ & $57 \cdot 7$ & $49 \cdot 3,65 \cdot 4$ & $22 \cdot 6^{\star \star}$ \\
\hline Inappropriate energy distribution & $70 \cdot 8$ & $64 \cdot 2,76 \cdot 8$ & $71 \cdot 2$ & $64 \cdot 6,77 \cdot 2$ & $59 \cdot 6$ & $51 \cdot 6,67 \cdot 2$ & $7 \cdot 0^{*}$ \\
\hline Calcium intake deficiency & $56 \cdot 8$ & $49.8,63.5$ & $64 \cdot 1$ & $57 \cdot 2,70 \cdot 6$ & $62 \cdot 1$ & $54 \cdot 1,69 \cdot 6$ & 2.5 \\
\hline Sodium excess & 58.2 & $51 \cdot 2,64.9$ & 50.4 & $43 \cdot 5,57 \cdot 3$ & 34.7 & $27 \cdot 4,42 \cdot 6$ & $20 \cdot 4^{\star \star}$ \\
\hline Energy excess & $47 \cdot 4$ & $40 \cdot 5,54.3$ & 49.5 & $42 \cdot 6,56 \cdot 4$ & 43.4 & $35 \cdot 6,51.5$ & 1.3 \\
\hline Fibre deficiency & 37.5 & $31 \cdot 0,44 \cdot 4$ & 32.5 & $26 \cdot 2,39 \cdot 3$ & $40 \cdot 3$ & $32 \cdot 7,48 \cdot 3$ & 2.5 \\
\hline Fats excess & 28.1 & $22 \cdot 2,34 \cdot 7$ & 36.7 & $30 \cdot 2,43 \cdot 6$ & 29.8 & $22 \cdot 8,37.5$ & 4.0 \\
\hline Low fish intake & $14 \cdot 0$ & $9 \cdot 7,19 \cdot 4$ & $10 \cdot 8$ & $7 \cdot 0,15 \cdot 8$ & $15 \cdot 5$ & $10 \cdot 3,22 \cdot 0$ & 1.9 \\
\hline Excess of simple sugars & $12 \cdot 2$ & $8 \cdot 1,17 \cdot 3$ & $5 \cdot 6$ & $2.9,9.6$ & 8.7 & $4 \cdot 8,14 \cdot 1$ & $5 \cdot 6$ \\
\hline Vitamin intake deficiency & $6 \cdot 1$ & $3 \cdot 2,10 \cdot 2$ & $5 \cdot 6$ & $2 \cdot 9,9.6$ & 5.5 & $2 \cdot 5,10 \cdot 3$ & 0.0 \\
\hline Excess of animal protein & 6.5 & $3 \cdot 6,10 \cdot 7$ & 3.3 & $1 \cdot 3,6 \cdot 6$ & 4.9 & $2 \cdot 1,9.5$ & 2.4 \\
\hline
\end{tabular}

Significant difference between age groups: ${ }^{*} P<0.05,{ }^{\star *} P<0.0001$.

\section{Discussion}

The relevance of the Mediterranean diet in the prevention of CVD has been known since 1986, when Keys et al. reported low incidence of mortality and CVD in a cohort from the Greek island of Crete in the Seven Countries Study ${ }^{(30)}$. We have already reported a low incidence of cerebrovascular diseases $^{(1)}$ in our population from the Aeolian Islands and in the current study we observed an excess of saturated fat, a high use of fish, a high consumption of fruits and vegetables, and a constant use of olive oil.

Fish consumption at least one or two times weekly has been demonstrated to exert a strong protective action against stroke ${ }^{(18,31-34)}$. Notably, $44.5 \%$ of our study 
Table 6 Percentage rates of daily alcohol consumption among the Aeolian population sample ( $n$ 586), June 2007

\begin{tabular}{lrrc}
\hline & Wine & Beer & Hard liquor \\
\hline Never or rarely & 71.2 & 93.7 & 98.3 \\
$1-2$ glasses & 23.6 & 5.0 & 1.2 \\
3 glasses & 2.9 & 0.7 & 0.0 \\
4-5 glasses & 1.9 & 0.7 & 0.3 \\
6 or more glasses & 0.3 & 0.0 & 0.2 \\
\hline
\end{tabular}

Table 7 Percentage rates of responses to the General Health Questionnaire, by age group, among the Aeolian population sample (n 586), June 2007

\begin{tabular}{lccc}
\hline & $\begin{array}{c}\text { Age }<46 \\
\text { years }\end{array}$ & $\begin{array}{c}\text { Age 46-65 } \\
\text { years }\end{array}$ & $\begin{array}{c}\text { Age }>65 \\
\text { years }\end{array}$ \\
\hline Normal stress $(<16)$ & 89.5 & 82.6 & 70.7 \\
Moderate stress $(16-20)$ & 7.0 & 6.6 & 8.0 \\
Severe stress $(>20)$ & 3.5 & 10.7 & 21.3 \\
\hline
\end{tabular}

$X^{2}=28.795 ; P<0.0001$.

population consumed fish once or twice weekly and $37.5 \%$ of the people consumed three to seven portions per week. The elevated frequency of fresh fruit and vegetable consumption observed in the Aeolian population ( $45.4 \%$ had them in almost every meal) reproduced the classic features of the Mediterranean diet ${ }^{(4)}$.

Studies performed in different countries showed an inverse relationship between stroke and fruit and vegetable use ${ }^{(35)}$. A protective dose-dependent effect has been confirmed by a meta-analysis ${ }^{(36)}$. Fruit and vegetable intake of more than 5 portions/d is associated with a marked reduction in the relative risk of stroke ${ }^{(36,37)}$. Vitamins, antioxidants, phenolic compounds, folates, minerals, hormones, plant enzymes and dietary fibre are probably the protective factors determining the evidenced positive effects $^{(4,5,25)}$. Sodium excess $(49 \cdot 0 \%)$ and calcium intake deficiency (60.9\%) found in the Aeolian participants were probably balanced by a relevant ingestion of potassiumrich foods such as fruits, vegetables and legumes which show anti-hypertensive effects and possible consequences on hypertension and risk of stroke $\mathrm{e}^{(38,39-50)}$.

The use of olive oil in the Aeolian diet is another favourable factor to prevent vascular risk and has a beneficial role in reducing LDL-cholesterol and increasing HDL-cholesterol. Moreover, olive oil seems to be associated with a reduction of systolic and diastolic pressure, due to the presence of other chemicals that have a vasodilator effect (polyphenols increase nitric acid) ${ }^{(51-53)}$.

Wine, beer and spirits were used by only a third of our Aeolian participants. In a meta-analysis, daily mild-moderate use of alcohol during meals has been proved to be a protective factor against cerebrovascular ischaemic diseases ${ }^{(54,55)}$.

It is possible to evoke an association between the Aeolian dietetic profile and the low incidence of stroke previously reported ${ }^{(1)}$; our hypothesis can be further supported by the significant role of diet on the risk of stroke and the correlation with many nutrients and risk factors of stroke (hypertension, diabetes, obesity, hyperhomocysteinaemia) ${ }^{(56,57)}$. However, causality is difficult to determine, and further studies are needed to clarify the independent role of the diet on the risk of stroke and cerebrovascular diseases. There are many confounders that need to be considered. For instance, there are differences in cerebrovascular risk factors between Aeolian inhabitants and the Italian population. In fact, hypertension, which is present in $31 \%$ of the Italian population ${ }^{(58)}$, has been identified in $20.5 \%$ of Aeolian people; and smoking, present in $22 \%$ of Italian people ${ }^{(59)}$, in our sample is present in $14.3 \%$ of participants. Conversely, the prevalence of diabetes was $6.3 \%$ in the Aeolian Islands whereas it was $4.6 \%$ in Italy, and the prevalence of hypercholesterolaemia was $13.5 \%$ in the Aeolian Islands $v$. $8.5 \%$ in the Italian population ${ }^{(59)}$. Interestingly, obesity (defined as BMI $\geq 30 \cdot 0 \mathrm{~kg} / \mathrm{m}^{2}$ ) was present in $18.5 \%$ of our sample and is higher than in the Italian general population $(9 \cdot 1 \%)^{(58)}$. This discrepant finding seems to be related to the excess of energy present in the diet of $47.1 \%$ of Aeolian people along with the limited physical activity.

Finally, we evaluated health status through the GHQ. We found a significant increase of distress in older people ( $>65$ years old), probably due to the lack of social activities on the islands that are mainly based on tourism and agriculture. However, in the majority of our sample we found a 'normal distress' level.

\section{Strengths and limitations}

The present study provides a descriptive analysis of the eating habits of 586 Aeolian people and is the first study that analyses the eating habits of the population of the Aeolian Islands, an interesting setting for its peculiarity in the incidence of neurological diseases. The population of these islands represents a confined and limited sample of the population of the Mediterranean basin.

Major limitations include the observational design and the small sample size. We also did not confirm by biochemical tests the vitamin deficiency and potassium intake, instead these were estimated indirectly by the quantity and quality of foods eaten. We did not include in the analysis some typical local foods, such as nuts or capers, key components of the Mediterranean diet, and lifestyle and physical activity. Finally, $13 \%$ of the individuals invited chose not to participate in the study and thus the presence of selection bias cannot be excluded.

\section{Conclusions}

Our study showed the eating habits of the population of the Aeolian Islands. This nutrition regimen was proved to 
be protective against cardio- and cerebrovascular diseases. It is reasonable to argue that the protective effect of the diet and the level of psychological distress found in Aeolian people might contribute to the low incidence of stroke found in the population.

\section{Acknowledgements}

Financial support: This research received no specific grant from any funding agency in the public, commercial or notfor-profit sectors. Conflict of interest: None. Authorship: P.L.S., R.S. and R.F.M. contributed to the study design. M.C., C.D.A., F.G., A.C., C.C. and M.C.F. performed data collection. R.S. and G.T. analysed the data. P.L.S., R.S., A.C. and R.F.M. wrote the article. Ethics of buman subject participation: This study was conducted according to the guidelines laid down in the Declaration of Helsinki, and all procedures involving human subjects were approved by the Institutional Review Board of the University of Messina. Written informed consent was obtained from all subjects.

\section{References}

1. Musolino R, La Spina P, Serra S et al. (2005) First-ever stroke incidence and 30-day case fatality in the Sicilian Aeolian archipelago, Italy. Stroke 36, 2738-2741.

2. Gallitto G, Serra S, La Spina P et al. (2005) Prevalence and characteristics of epilepsy in the Aeolian islands. Epilepsia 46, $1828-1835$.

3. Morgante L, Nicoletti A, Epifanio A et al. (2008) Prevalence of Parkinson's disease and other types of parkinsonism in the Aeolian Archipelago, Sicily. Parkinsonism Relat Disord 14, 572-575.

4. Gerber M \& Hoffman R (2015) The Mediterranean diet: health, science and society. Br J Nutr 113, Suppl. 2, S4-S10.

5. Vasto S, Barera A, Rizzo C et al. (2014) Mediterranean diet and longevity: an example of nutraceuticals? Curr Vasc Pharmacol 12, 735-738.

6. Park YM, Steck SE, Fung TT et al. (2016) Mediterranean diet and mortality risk in metabolically healthy obese and metabolically unhealthy obese phenotypes. Int $J$ Obes (Lond) 40, 1541-1549.

7. Ravera A, Carubelli V, Sciatti E et al. (2016) Nutrition and cardiovascular disease: finding the perfect recipe for cardiovascular health. Nutrients $\mathbf{8}, \mathrm{E} 363$.

8. Ros E, Martinez-Gonzalez MA, Estruch R et al. (2014) Mediterranean diet and cardiovascular health: teachings of the PREDIMED study. Adv Nutr 5, issue 3, 330S-336S.

9. Alkerwi A, Vernier C, Crichton GE et al. (2015) Crosscomparison of diet quality indices for predicting chronic disease risk: findings from the Observation of Cardiovascular Risk Factors in Luxembourg (ORISCAV-LUX) study. $\mathrm{Br}$ J Nutr 113, 259-269.

10. Giacosa A, Barale R, Bavaresco L et al. (2013) Cancer prevention in Europe: the Mediterranean diet as a protective choice. Eur J Cancer Prev 22, 90-95.

11. Estruch R, Ros E, Salas-Salvadó J et al. (2013) Primary prevention of cardiovascular disease with a Mediterranean diet. N Engl J Med 368, 1279-1290.

12. Sofi F, Cesari F, Abbate R et al. (2008) Adherence to Mediterranean diet and health status: meta-analysis. BMJ 337, 673-675.
13. Tsivgoulis G, Judd S, Letter AJ et al. (2013) Adherence to a Mediterranean diet and risk of incident cognitive impairment. Neurology 80, 1684-1692.

14. Singh B, Parsaik AK, Mielke MM et al. (2014) Association of Mediterranean diet with mild cognitive impairment and Alzheimer's disease: a systematic review and meta-analysis. J Alzheimers Dis 39, 271-282.

15. Alcalay RN, Gu Y, Mejia-Santana H et al. (2012) The association between Mediterranean diet adherence and Parkinson's disease. Mov Disord 27, 771-774.

16. Psaltopoulou T, Sergentanis TN, Panagiotakos DB et al. (2013) Mediterranean diet, stroke, cognitive impairment, and depression: a meta-analysis. Ann Neurol $\mathbf{7 4 ,}$ $580-591$.

17. Lourida I, Soni M, Thompson-Coon J et al. (2013) Mediterranean diet, cognitive function, and dementia: a systematic review. Epidemiology 24, 479-489.

18. He K, Song Y, Daviglus ML et al. (2004) Fish consumption and incidence of stroke: a meta-analysis of cohort studies. Stroke 35, 1538-1542.

19. He FJ, Nowson CA \& MacGregor GA (2006) Fruit and vegetable consumption and stroke: meta-analysis of cohort studies. Lancet 367, 320-326.

20. Martínez-González MA, Dominguez LJ \& Delgado-Rodríguez M (2014) Olive oil consumption and risk of CHD and/ or stroke: a meta-analysis of case-control, cohort and intervention studies. Br J Nutr 112, 248-259.

21. Tsivgoulis G, Psaltopoulou T, Wadley VG et al. (2015) Adherence to a Mediterranean diet and prediction of incident stroke. Stroke 46, 780-785.

22. Demarin V, Lisak M \& Morovic S (2011) Mediterranean diet in healthy lifestyle and prevention of stroke. Acta Clin Croat 50, 67-77.

23. Misirli G, Benetou V, Lagiou P et al. (2012) Relation of the traditional Mediterranean diet to cerebrovascular disease in a Mediterranean population. Am J Epidemiol 176, 1185-1192.

24. Zhang X, Shu L, Si C et al. (2015) Dietary patterns and risk of stroke in adults: a systematic review and meta-analysis of prospective cohort studies. J Stroke Cerebrovasc Dis 24, $2173-2182$.

25. Strazzullo P, Scalfi L, Branca F et al. (2004) Nutrition and prevention of ischemic stroke: present knowledge, limitations and future perspectives. Nutr Metab Cardiovasc Dis 14, 97-114.

26. De Lorgeril M, Salen P, Martin JL et al. (1999) Mediterranean diet, traditional risk factors, and the rate of cardiovascular complications after myocardial infarction: final report of the Lyon Diet Heart Study. Circulation 99, 779-785.

27. Martínez-González MA, Salas-Salvadó J, Estruch $\mathrm{R}$ et al. (2015) Benefits of the Mediterranean diet: insights from the PREDIMED Study. Prog Cardiovasc Dis 58, 50-60.

28. Buscemi S, Rosafio G, Vasto S et al. (2015) Validation of a food frequency questionnaire for use in Italian adults living in Sicily. Int J Food Sci Nutr 66, 426-438.

29. Politi PL, Piccinelli M \& Wilkinson G (1994) Reliability, validity and factor structure of the 12-item General Health Questionnaire among young males in Italy. Acta Psychiatr Scand 90, 432-437.

30. Keys A, Menott A, Karvonen MJ et al. (1986) The diet and 15-year death rate in the Seven Countries Study. Am J Epidemiol 185, 1130-1142.

31. Iso H (2001) Intake of fish and omega-3 fatty acids and risk of stroke in women. JAMA 285, 304-312.

32. Bouzan C, Cohen JT, Connor WE et al. (2005) A quantitative analysis of fish consumption and stroke risk. Am J Prev Med 29, 347-352.

33. Chowdhury R, Stevens S, Gorman D et al. (2012) Association between fish consumption, long chain omega 3 fatty acids, and risk of cerebrovascular disease: systematic review and meta-analysis. BMJ 345, e6698. 
34. Siegel G \& Ermilov E (2012) Omega-3 fatty acids: benefits for cardio-cerebro-vascular diseases. Atherosclerosis $\mathbf{2 2 5}$, 291-295.

35. Joshipura KJ, Ascherio A, Manson JE et al. (1999) Fruit and vegetable intake in relation to risk of ischemic stroke. JAMA 282, 1233-1239.

36. Dauchet L, Amouyel P \& Dallongeville J (2005) Fruit and vegetable consumption and risk of stroke: a meta-analysis of cohort studies. Neurology 65, 1193-1197.

37. Hu D, Huang J, Wang Y et al. (2014) Fruits and vegetables consumption and risk of stroke: a meta-analysis of prospective cohort studies. Stroke 45, 1613-1619.

38. He J (1999) Dietary sodium intake and subsequent risk of cardiovascular disease in overweight adults. JAMA 282, 2027-2034.

39. Tuomilehto J, Jousilahti P, Rastenyte D et al. (2001) Urinary sodium excretion and cardiovascular mortality in Finland: a prospective study. Lancet 357, 848-851.

40. Nagata C, Takatsuka N, Shimizu N et al. (2004) Sodium intake and risk of death from stroke in Japanese men and women. Stroke 35, 1543-1547.

41. Iso H, Stampfer MJ, Manson JE et al. (1999) Prospective study of calcium, potassium, and magnesium intake and risk of stroke in women. Stroke 30, 1772-1779.

42. Abbott RD, Curb JD, Rodriguez BL et al. (1996) Effect of dietary calcium and milk consumption on risk of thromboembolic stroke in older middle-aged men. The Honolulu Heart Program. Stroke 27, 813-818.

43. Umesawa M, Iso H, Date C et al. (2006) Dietary intake of calcium in relation to mortality from cardiovascular disease: the JACC study. Stroke 37, 20-26.

44. Aaron KJ \& Sanders PW (2013) Role of dietary salt and potassium intake in cardiovascular health and disease: a review of the evidence. Mayo Clin Proc 88, 987-995.

45. Jayedi A, Ghomashi F, Zargar MS et al. (2018) Dietary sodium, sodium-to-potassium ratio, and risk of stroke: a systematic review and nonlinear dose-response metaanalysis. Clin Nutr. Published online: 1 June 2018. doi: 10.1016/j.clnu.2018.05.017.

46. Sluijs I, Czernichow S, Beulens JWJ et al. (2014) Intakes of potassium, magnesium, and calcium and risk of stroke. Stroke 45, 1148-1150.
47. Adebamowo SN, Spiegelman D, Willett WC et al. (2015) Association between intakes of magnesium, potassium, and calcium and risk of stroke: 2 cohorts of US women and updated meta-analyses. Am J Clin Nutr 101, 1269-1277.

48. Vinceti M, Filippini T, Crippa A et al. (2016) Meta-analysis of potassium intake and the risk of stroke. J Am Heart Assoc 5, e004210.

49. D'Elia L, Iannotta C, Sabino P et al. (2014) Potassium-rich diet and risk of stroke: updated meta-analysis. Nutr Metab Cardiovasc Dis 24, 585-587.

50. Willey J, Gardener H, Cespedes S et al. (2017) Dietary sodium to potassium ratio and risk of stroke in a multiethnic urban population: the northern Manhattan study. Stroke $\mathbf{4 8}$, 2979-2983.

51. Schwingshackl L \& Hoffmann G (2014) Monounsaturated fatty acids, olive oil and health status: a systematic review and meta-analysis of cohort studies. Lipids Health Dis 13, 154 .

52. Covas M-I, Konstantinidou V \& Fitó M (2009) Olive oil and cardiovascular health. J Cardiovasc Pharmacol 54, 477-482.

53. Larsson SC (2013) Dietary fats and other nutrients on stroke. Curr Opin Lipidol 24, 41-48.

54. Reynolds K, Lewis B, Nolen JDL et al. (2003) Alcohol consumption and risk of stroke. JAMA 289, 579-588.

55. Patra J, Taylor B, Irving H et al. (2010) Alcohol consumption and the risk of morbidity and mortality for different stroke types - a systematic review and meta-analysis. BMC Public Health 10, 258.

56. Lakkur S \& Judd SE (2015) Diet and stroke. Stroke $\mathbf{4 6}$, 2007-2011.

57. Gariballa SE (2000) Nutritional factors in stroke. Br J Nutr 84, 5-17.

58. ISTAT (1999) Indagine multiscopo. Condizioni di salute e ricorso ai servizi sanitari. https://www.istat.it/it/archivio/ 5471 (accessed December 2018).

59. OSSFAD-Istituto Superiore di Sanità (2008) Il fumo in Italia (DOXA 2008). http://old.iss.it/binary/ofad/cont/Il\%20fumo \%20in\%20Italia\%202008.1212480126.pdf (accessed December 2018). 